OPEN ACCESS

Edited by:

Mathias Fridahl,

Linköping University, Sweden

Reviewed by:

Jacopo Giuntoli,

Independent Researcher, Montecatini

Terme, Italy

Dilip Khatiwada,

Royal Institute of Technology, Sweden

${ }^{*}$ Correspondence:

Daniel L. Sanchez sanchezd@berkeley.edu

Specialty section:

This article was submitted to Negative Emission Technologies, a section of the journal Frontiers in Climate

Received: 08 February 2021 Accepted: 13 April 2021

Published: 14 May 2021

Citation:

Sanchez DL, Fingerman K, Herbert C and Uden S (2021) Policy Options for

Deep Decarbonization and Wood Utilization in California's Low Carbon Fuel Standard. Front. Clim. 3:665778. doi: 10.3389/fclim.2021.665778

\section{Policy Options for Deep Decarbonization and Wood Utilization in California's Low Carbon Fuel Standard}

\author{
Daniel L. Sanchez ${ }^{1 *}$, Kevin Fingerman ${ }^{2}$, Claudia Herbert ${ }^{1}$ and Sam Uden ${ }^{3}$ \\ ${ }^{1}$ Department of Environmental Science, Policy and Management, University of California, Berkeley, Berkeley, CA, \\ United States, ${ }^{2}$ Environmental Science and Management, Humboldt State University, Arcata, CA, United States, ${ }^{3}$ School of \\ Earth and Environmental Sciences, University of Queensland, Brisbane, QLD, Australia
}

California's Low Carbon Fuel Standard (LCFS) is one of the most important policies to develop and deploy low-carbon and carbon-negative fuels. Yet, because the LCFS is designed to deliver the lowest-cost carbon intensity $(\mathrm{Cl})$ reductions possible in the transportation fuel system, it may fail to deliver technologies that would be poised to offer deeper decarbonization or other ancillary benefits to California's people and environment. We contemplate administrative changes to the LCFS to further stimulate the commercialization of promising low-carbon and carbon-negative fuels. To do so, we examine promising technical pathways, their barriers to commercialization, and recent administrative actions by the CA Air Resources Board (ARB) under the LCFS to promote novel lower-carbon fuels. We propose three actions that ARB could undertake to promote commercialization within existing authorities. To commercialize low-carbon and carbon negative fuel, including those derived from forest residue feedstocks, ARB could: (1) embrace the most up-to-date science regarding lifecycle greenhouse gas emissions, (2) create additional, targeted incentives for very low-carbon or carbon-negative fuels through a volumetric technology carve-out or credit multiplier, and (3) ensure that the LCFS stimulates the best-performing fuels across a variety of sustainability parameters.

Keywords: carbon dioxide removal, climate policy, forest biomass, California, low carbon fuel standard

\section{INTRODUCTION}

\section{Deep Decarbonization in California's Low Carbon Fuel Standard}

California's Low Carbon Fuel Standard (LCFS) is emerging as one of the most important policies to develop low-carbon and carbon-negative fuels, which have a very low or negative carbon intensity (CI) based on lifecycle assessment. Offering one of the highest carbon prices of any emissions market in the world, the LCFS is spurring the development of cutting-edge low-carbon fuel pathways that might otherwise never come to market. The years 2019 and 2020 saw the announcement of numerous commercial-scale cellulosic biofuel, bioenergy with carbon capture and sequestration (BECCS), landfill and dairy biogas, and direct air capture (DAC) projects, many of which explicitly cited revenues from CA's LCFS as a motivation (Aemetis, 2019; Rathi, 2019). These fuels play a pivotal role in California, national, and international action to address climate change (The White House, 2016; Rogelj et al., 2018). 
Yet successful commercialization of low-carbon and carbonnegative fuels is far from certain, despite policy support from the LCFS. Commercial-scale cellulosic biofuels, for instance, have seen several high-profile failures in recent years (Lynd et al., 2017). Most negative emissions technologies face challenges related to both technical and commercial immaturity (Lomax et al., 2015). Without modifications to the LCFS, these promising technologies might be locked out by more established and cheaper, but less carbon-reducing alternatives. Indeed, lack of "demand pull" has been cited as a primary barrier to the deployment of carbon-negative bioenergy within national climate change policies (Fridahl et al., 2020; Schenuit et al., 2021).

The transportation sector represents $41 \%$ of total GHG emissions in California, and recently surpassed electric power to become the largest emissions sector nationwide (CARB, 2019a). This is because emissions from electric power generation, long the most significant sector, are comparatively easy and inexpensive to reduce. Emissions reductions from transport, on the other hand, are comparatively challenging to achieve. Necessary change in this sector is inhibited by market barriers such as technology lock-in, the low price elasticity of fuel demand, and the need for coordination among fuel producers, distributors, and consumers. Furthermore, the marginal abatement cost of transportation emission reductionsespecially through fuel switching-is comparatively high, meaning an economy-wide carbon price, while an economically efficient approach to emission abatement, is unlikely to achieve significant near-term reductions from transport at politicallyacceptable carbon prices (Lutsey and Sperling, 2009; van der Zwaan et al., 2013). For example, U.S. government analysis of the American Clean Energy and Security Act of 2009 determined that a nationwide cap-and-trade system would yield almost no emission reduction in the transport sector, which would account for over $50 \%$ of total emissions nationwide in 2050 (Fawcett, 2010).

Spurring near-term emission reductions through transportation fuel switching is the reason the LCFS is necessary. The November 2020 credit price under CA's cap \& trade system averaged $\$ 16.93$, while the credit price in the LCFS credits averaged $\$ 199$ per metric ton (CARB, 2021a,b). This implies that the changes being spurred by the LCFS would indeed not come about through an economy-wide carbon price alone. The LCFS and other sector-specific policies are necessary to drive the development of technologies and markets that will ultimately be necessary for deeper emissions reductions, meeting California's goal of carbon neutrality in 2045 (Baker et al., 2019). As has been shown before in the renewable energy space, these near-term costs can ultimately stimulate technology development leading to cost reductions such that these targeted policies are no longer needed. One key element in the pursuit of deep emissions cuts from transportation will be the deployment of low-carbon alternative fuels, an outcome that is the direct target and result of California's LCFS.

A carbon price mechanism will deliver the cheapest mitigation available in the system. However, as Vogt-Schilb and Hallegatte, point out, this can create a conflict between what they refer to as "cheap" and "deep" abatement options (Vogt-Schilb and
Hallegatte, 2014). They state that "the measures required to achieve ambitious emission reductions cannot be implemented overnight, the optimal strategy to reach a short-term target depends on longer-term targets. For instance, the best strategy to achieve Europe's $-20 \%$ by 2020 target may be to implement some expensive, high-potential, and long-to-implement options required to meet the $-75 \%$ by 2050 target. Using just the cheapest abatement options to meet the 2020 target can create carbon-intensive lock-in and make the 2050 target too expensive to reach."

This is the reason the LCFS exists was adopted by California's Air Resources Board all; it will help spur early action on deeper abatement pathways that will be necessary in the long run (Exec. Order No. S-01-07 by Governor Arnold Schwarzenegger, 2007; Farrell et al., 2007). However, this problem also exists within the LCFS system, as it is also a market designed to deliver the cheapest fuel carbon intensity reductions possible today rather than those capable of delivering the deepest decarbonization in the long term. Just as California requires the LCFS policy to stimulate action in the transportation fuels space-action that will eventually be necessary to reach deep mitigation targets - the State may also require action within the LCFS program to spur development of technologies capable of deeper mitigation than those that are emerging currently from the LCFS market. It is also worth considering whether the LCFS can be leveraged to achieve broader state goals beyond only fuel carbon intensity (CI) reduction, such as wildfire risk reduction.

Put more plainly, the LCFS has not yet led to wide-scale commercialization of very low-carbon or carbon-negative fuels. Instead, early targets were met by blending conventional cropbased biofuels (Figure 1) that were able to deliver 1-5\% average fuel CI reductions but do not have a low enough carbon footprint to play a role in reaching $10-20 \%$ reduction targets. Compliance has shifted to lower carbon first-generation fuels such as biodiesel and renewable diesel from recycled vegetable and other waste oils, but these are supply-limited, hampering their ability to drive deep decarbonization (Christensen and Hobbs, 2016). As demand for these costly fuels has increased, credit prices have risen dramatically.

\section{The Low-Carbon Fuel Landscape in California}

California and its neighbors have numerous commercial-scale low-carbon and carbon-negative fuels production facilities in various stages of development (Table 1). These include biofuels from very low-carbon biomass feedstocks-especially residues from sustainable forest management-and those using carbon capture and sequestration (CCS) technologies to make lowcarbon and carbon-negative fuels.

\section{The Forest/Fuel/Air Quality Nexus in California}

California's forest management crisis has important implications for public safety, biodiversity conservation, water resource management, air quality, climate change, and the state's 


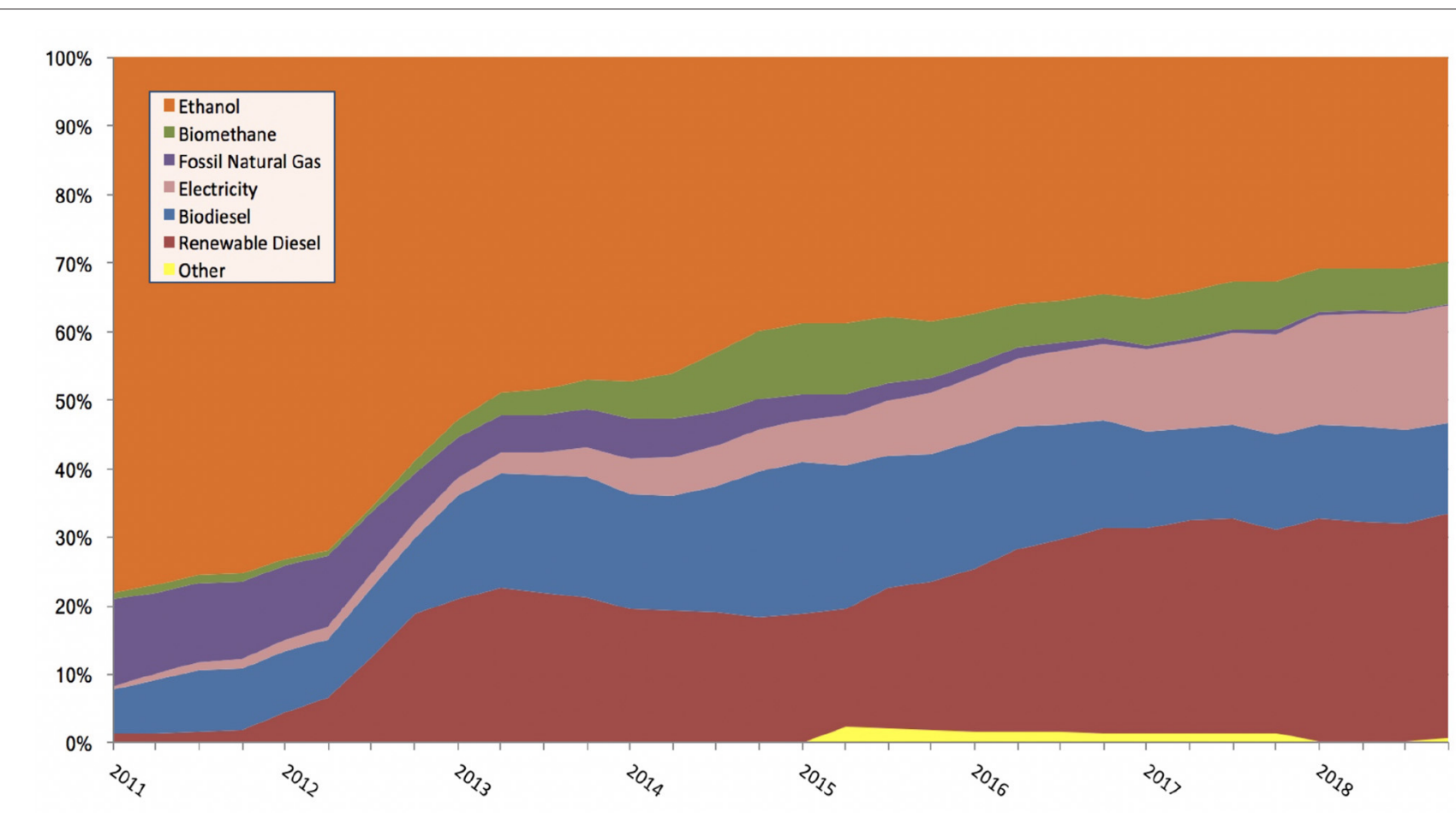

FIGURE 1 | Yearly rolling average percentage of credits by fuel type from Q1 2011 to quarter 3 (Q3) 2019. Total credits generated grew more than 10 -fold over this period from 328,000 metric tons in quarterly in 2011 to 3.48 million metric tons quarterly. Reproduced from CARB (2021c).

TABLE 1 | Characterization of low-carbon and carbon-negative pathways proposed in California.

\begin{tabular}{|c|c|c|c|c|c|c|c|}
\hline Product & Feedstock required & Example & Carbon removal & $\begin{array}{l}\text { TRLi } \\
(1-9)\end{array}$ & $\begin{array}{l}\text { CRLii } \\
(1-9)\end{array}$ & Project location & $\begin{array}{c}\text { Capital cost } \\
\text { (\$ million) }\end{array}$ \\
\hline \multicolumn{8}{|c|}{ Biofuels from woody biomass, including biofuels with CCS } \\
\hline $\begin{array}{l}\text { Ethanol via gas } \\
\text { fermentation }\end{array}$ & 133,000 BDT/year & Aemetis Inc. & No & 8 & 6 & Riverbank, CA & $158^{b}$ \\
\hline Renewable natural gas & 250,000 BDT/year & GTI Stockton & Possible (CCS) & 6 & 5 & Stockton, CA & $340^{c}$ \\
\hline
\end{tabular}

a Dihn and Manternach, 2019.

bLane, 2018.

${ }^{c}$ GTI, 2019.

i: Technology Readiness Level.

ii: Commercial Readiness Level.

economy ${ }^{1}$. Wildfires in California during the 2018 fire season released about 68 million tons of $\mathrm{CO}_{2}$ equivalent. This accounts for $15 \%$ of California's total carbon footprint and is comparable in magnitude to emissions from the state's electricity generation in the same year. The 2018 Camp Fire alone is estimated to have cost $\$ 16.5$ billion in economic losses (Löw, 2019).

Because of these cross-cutting impacts, especially in the wake of 2 years of severe wildfires, significant political and economic resources are now being mobilized to promote sustainable

$\overline{{ }^{1} \text { Little Hoover Commission, } 2018 .}$ management of California's forests. Historically, restoration treatments have been "carried" economically by the concurrent harvest of merchantable sawlogs as part of the management plan. Where this is not feasible, other sources of funding must be applied to support forest management.

Recent research by the Board of Forestry's Joint Institute for Wood Products Innovation has found that the LCFS could be an important source of revenue for forest restoration in California (Sanchez et al., 2020). In short, innovative wood products, including low-carbon and carbon-negative fuels, hold the potential to support carbon-beneficial, sustainable forest management in California. Innovative wood products can 


\section{Open Burning Emissions to Increase Without Cost Effective Alternative}

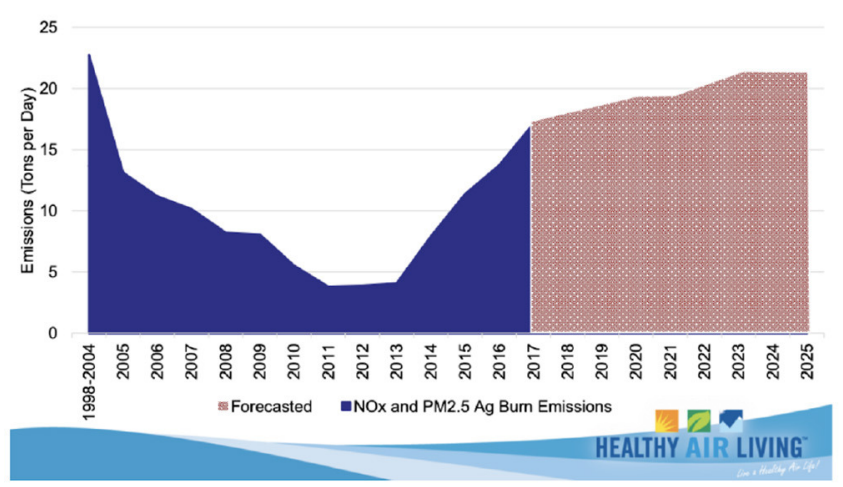

\section{Open Burning Emissions can Decrease With Cost Effective Alternative}

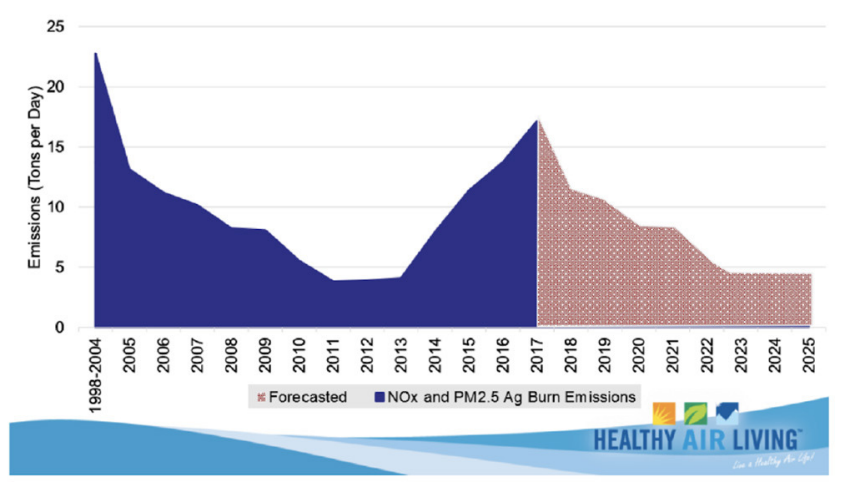

FIGURE 2 | Expected emissions of key health-impacting air pollutants from agricultural burning in the San Joaquin Valley. Reproduced from Olsen (2017).

support the state of California in increasing the pace and scale of forest management and restoration efforts, building local capacity, strengthening regional collaboration, supporting innovation, and promoting carbon storage.

It is important to note these technologies can employ either woody forest biomass or agricultural biomass, such as orchard and vineyard wastes. Agricultural biomass has numerous economic and logistical advantages over forest biomass: it is often cheaper, closer to existing infrastructure, and co-located with suitable geology for geologic $\mathrm{CO}_{2}$ sequestration.

There is a significant air quality benefit of diverting otherwiseburned biomass. From 2005-2012, open burning of agricultural residue in the San Joaquin Valley had been reduced by over $80 \%$, but drought and the shutdown of six biopower facilities in the region led to a significant increase in open burning, bringing it back above 2005 levels. Most of this increase is from open burning of biomass from pruning and removal of orchard trees. Under business-as-usual projections, open burning of agricultural residues-and the resultant emissions of healthharming air pollutants-are expected to increase, as indicated in Figure 2.

Working to find alternatives to open burning of agricultural waste is a major stated priority for the San Joaquin Valley Air Pollution Control District and other Air Districts (San Joaquin Valley Air Pollution Control District, 2018). Not only is this a public health concern, but it is also a significant environmental justice consideration, as recognized disadvantaged communities are disproportionately exposed to the emissions from these open burns (OEHHA, 2017). Pile burning of forest residues, as well as exposure to wildfire smoke, are similarly significant public health concerns, but under the current LCFS structure, there is no way to support pathways that offer reductions in criteria pollutant emissions.

We note that other sources of biomass have less favorable environmental impacts than those we consider in this paper. Potentially negative impacts related to forest residue removal include degradation of ecosystem condition and reduction of biodiversity (Camia et al., 2021). Managing these complex tradeoffs in forest-based climate change mitigation is subject to intense debate amongst academics, NGOs, and policymakers.

\section{CCS Technologies}

In addition to biomass-based processes, it is possible to create low-carbon and carbon-negative fuels using carbon capture and sequestration (CCS) in fuels production processes. Opportunities include carbon capture and sequestration of existing $\mathrm{CO}_{2}$ emissions from fuels production. When ARB announced its 2019 changes to the LCFS, they pointed out that the CCS protocol would be particularly useful for ethanol producers, allowing producers to reduce CI by up to $40 \%$ (CARB, 2018a). To date, there is one CCS project submitted to ARB for approval. This project is part of an existing starch ethanol facility in North Dakota that will capture about 181,000 metric tons of $\mathrm{CO}_{2}$ annually from starch fermentation and inject into a geologic formation 6,500 $\mathrm{ft}$ below the ethanol facility (Red Trail Energy, LLC, 2019; CARB, 2020a).

Despite the large financial incentives for low-carbon and carbon-negative fuels in California, these fuels may require additional support to be successfully commercialized. This is because low-carbon and carbon-negative fuels have not overcome the so-called "commercialization valley of death," which can occur for technologies that have already demonstrated proof of concept but still require large capital infusions to demonstrate that their design and manufacturing processes can be brought to full commercial scale (e.g., a first-of-a-kind full-scale power plant or manufacturing facility) (Jenkins and Mansur, 2011). Possible reasons for this outcome include low technical and commercial maturity, high capital costs, feedstock supply uncertainty for forest biomass, stability of revenues and LCFS credit prices, and permitting challenges.

\section{Relevant Administrative Actions Under LCFS}

Prior administrative action by ARB can inform feasible LCFS interventions to promote deep decarbonization. Most notably, in 2018, ARB board members amended the LCFS to broaden 
the program's focus and promote engineered carbon removal technologies (CARB, 2018a). Taking effect January 1, 2019, the re-adoption of the LCFS extended the program to 2030 with a targeted 20 percent CI decrease from 2010 levels. Additionally, the re-adoption imposed a CI gasoline and diesel standard for all post-2030 years that keeps the CI from increasing over time (CARB, 2020b). Along with extending the timeline for LCFS, the re-adoption expanded credit-generation opportunities to include non-alternative fuel pathway crediting, encompassing carbon capture and sequestration (CCS), low-carbon electricity generation, and building infrastructure for Zero Emissions Vehicles. The decision to extend the market to 2030 signaled ARB's commitment to the LCFS framework ${ }^{2}$. More recently, Governor Newsom directed ARB to develop and propose strategies to continue the State's current efforts to reduce the carbon intensity of fuels beyond 2030 (Exec. Order No. N-79-20, 2020).

\section{Inclusion of Carbon Capture in LCFS}

Project Based Crediting for CCS, a non-fuel credit-generating pathway, was added in 2018 (Townsend and Havercroft, 2019). This was the result of a multi-year process at ARB to integrate CCS with state climate policies, including 2050 state climate goals (CARB, 2017). To qualify for this protocol, a project must be part of a low carbon fuel pathway (Tier 2 pathway), a refinery investment (e.g., steam methane reforming), innovative crude (e.g., co-gen at oil field), or direct air capture (CARB, 2018b). CCS projects must inject the carbon into a saline reservoir, depleted oil and gas reservoirs, or oil and gas reservoirs used for $\mathrm{CO}_{2}$-enhanced oil recovery and secure the carbon belowground for at least 100 years, meeting the permanence requirement (CARB, 2019b). Before credits are issued, a permanence certification needs to be issued, which includes a sequestration site certification and a CCS project certification. Both of these certifications require third-party review, and take an estimated 6 months for crediting (CARB, 2018b).

The LCFS CCS protocol provides flexibility on where projects can occur and allows stacking tax credits to promote maximum development and deployment of CCS technologies. Projects can occur anywhere in the world, but non-DAC projects must be associated with fuel sold in California. Projects can claim both LCFS credits and the federal 45Q tax credit for carbon oxide sequestration, increasing the value of CCS to $\sim \$ 250 /$ ton CO2 sequestered (Credit for Carbon Oxide Sequestration, 2011).

\section{Zero Emissions Vehicle Infrastructure Capacity}

Prior to the 2018 amendments, electric utilities could optin to participating in the LCFS, producing electricity as a transportation fuel and supporting electric vehicles (EV). Utilities were eligible to generate LCFS credits for electricity they provided to charge EVs, and used credit revenue to provide

\footnotetext{
${ }^{2}$ Extrapolating the trend in historic weekly averages of LCFS credits prices leading up to the announcement of the market extension (5/2/2016-9/17/2018) to forecast the price a year from the announcement for linear forecasting, the expected value is $\$ 169$ and the actual market value was $\$ 195$.
}

a one-time, post-purchase rebate to utility customers who had purchased an EV. The 2019 amendments expanded the role of electricity providers and support for EVs, by expanding creditgenerating opportunities based on supporting both EV charging infrastructure and purchasing. The 2019 amendments did not change how LCFS counts utility electricity generation, but it does have two notable contributions to changing LCFS credit generating opportunities: awarding credits for capacity rather than dispensed fuel, and further prioritizing deployment of EVs through a point-of-purchase EV rebate (Zheng, 2019a).

The zero emissions vehicle (ZEV) amendments to LCFS cover Hydrogen Refueling Infrastructure (HRI) and Direct Current Fast Charging Infrastructure (FCI) per Executive Order B-48-18 and Board Resolution 18-17 (CARB, 2018c). As of October 30, 2020, 52 hydrogen stations and 436 DC fast chargers at 91 sites have been approved for ZEV infrastructure crediting (CARB, 2021d). As stations reach full utilization, credits decrease in value, creating some first mover advantage (CARB, 2018c). By the end of 2025, these credits will sunset and, throughout its lifetime, are not to exceed $5 \%$ of program deficits (Witcover, 2018). The pointof-purchase rebate is still under development but is intended to further incentivize Californians purchasing EVs, now better supported by EV charging infrastructure (Zheng, 2019b).

\section{Credit Clearance Market}

$\mathrm{ARB}$ can also create price certainty through the Credit Clearance Market (CCM). The CCM is used to create a price cap, creating an annual market that allows deficit holders to trade at a set maximum (\$200 in 2016 dollars) with credit holders that have agreed to participate (Stillwater Associates L. L. C, 2018; CARB, 2019c). This CCM prevents daily trades from exceeding too far above this $\$ 200 / \mathrm{T}$ ceiling because deficit holders have either the CCM or deficit banking opportunities at the end of the compliance year to settle deficits. As CI standards decline and it becomes more difficult to comply with LCFS fuel averages, the CCM will become increasingly important. Staff at ARB have indicated that the CCM should be used for cost containment to prevent demand-driven price spikes.

The price cap is maintained through granting electric utilities LCFS credits in the current year that are "borrowed" from that utility's future EV charging credit generation. The utilities are then obligated to sell these credits in the CCM and to invest proceeds from these "holdback" credits into subsidies for new EV purchases (the Clean Fuel Rewards program) and in the installation of EV charging infrastructure in disadvantaged communities (CARB, 2019d).

\section{Changes to Target Stringency and End Date}

Another policy design impacting price certainty is target stringency-or the ambition of CI targets-and the rate of ratcheting down CI averages. To encourage large capital investments and changes in supply-chains necessary for decarbonizing transportation, it is important for the policy to have high target stringency so that regulated entities have the necessary market certainty to stimulate investment. In 2018, ARB made minor changes to the short-term CI targets leading 
up to 2020 and signaled major commitment to the LCFS by extending the market to 2030 .

\section{ACTIONABLE RECOMMENDATIONS}

We discuss three actions that ARB could undertake to promote commercialization of low-carbon and carbon-negative biofuels within their existing authorities.

\section{Ensure Up-To-Date Accounting of Avoided Emissions Benefits}

Lifecycle assessment as a regulatory tool is a complex topic, which often involves normative choices (Breetz, 2017). For instance, CA has included indirect land use change in its lifecycle carbon accounting under the LCFS, while the European Union has excluded it under its Renewable Energy Directive (Camia et al., 2021). Using best-available science around the lifecycle benefits and drawbacks of biofuels can guide future ARB action.

The LCFS carbon accounting framework currently does not account for emissions of biogenic carbon. While appropriate for some agricultural biofuels for which the time period of carbon sequestration is short (i.e., $<1$-year), it raises concerns when applied to forest biomass, which may sequester carbon for decades. Additionally, the framework also fails to account for avoided emissions from pile burning or decay of woody biomass, which is common practice in much of California (Springsteen et al., 2015). These emissions should be quantified in pathway CI calculations, providing additional incentives based on the actual emissions reductions from these feedstock sources.

Further, ARB should pursue research internally and externally to identify and reduce uncertainties related to these avoided emissions scenarios. For example, the frequency with which woody biomass, particularly forest residues, are pile burned in California is not currently tracked despite its obvious importance to fire risk, carbon storage, air quality and other environmental concerns. Tracking business-as-usual fate of woody biomass will aid in accurate accounting for the emissions avoided by their utilization. Finally, there is little empirical data on methane emissions from biomass piles-either in the field or at industrial facilities (California Board of Forestry Fire Protection, 2020). Given methane's importance as a GHG, this question warrants empirical study in the California context in order to accurately account for the net emissions impact of residue mobilization.

\section{Provide Additional Incentives for Very Low-Carbon and Carbon Negative Fuels}

Additional incentives to promote deeper decarbonization technologies could take several forms within the LCFS. In this section, we highlight two possibilities: a volumetric technology carve-out and a credit multiplier.

\section{Volumetric Technology Carve-Out}

A volumetric technology carve-out could be applied to a target fuel, such as one achieving a very low or negative CI score, or one made from biomass that would otherwise have been burned, leading to significant air quality impairments. A carveout could require blenders to procure some fraction of their fuel from that source (or pay someone else to do so). Similar carve-outs are commonly used in Renewable Portfolio Standard (RPS) policies to deliver priority goals. While an RPS is generally designed to be technology-neutral like the LCFS, such carveouts require regulated entities to procure a set percentage or amount of their power from operations of a certain type. This allows policymakers to use the RPS to achieve goals such as the development of emerging renewable energy technologies or support for local manufacturing. A similar approach could be implemented in the LCFS. Such an approach could allow $\mathrm{CA}$ to reduce the unintended consequences of an expansion of forest-biomass fuels, including use of biomass with less desirable environmental impacts.

For example, if the State identifies a priority, such as the creation of a renewable hydrogen industry utilizing diversion of woody forest residues that would otherwise have been open pile burned, or avoided flaring of landfill gas, the LCFS could mandate a fixed or rising number of MJ of fuel be generated from this source annually, obligating parties to purchase their "share" of these fuels or credits. The key challenge posed in this case is that such a "quantity" measure does not control cost. If a very small set of facilities are able to produce the qualifying fuel, the cost of these credits could rise rapidly. A carve-out could be more appropriate once the industries in question have reached commercial maturity, in order to use the LCFS system to drive further deployment of operational technologies.

\section{Credit Multiplier}

If a certain type of fuel or feedstock source is found to deliver priority goals, additional LCFS credits could be offered to manufacturers of that fuel, e.g., 1.2 or $1.5 \mathrm{MJ}$ of credit for every MJ of fuel delivered. Specific credit multiplier values would be determined based on current market conditions and cost of production. One down-side of such a policy is that it reduces the actual GHG reductions delivered by the LCFS, since it would in effect create credits for low-carbon fuels that were not delivered.

This is not a novel concept. For example, the US Corporate Average Fuel Economy (CAFE) Standard is designed to increase the fuel economy of the vehicles sold in the US. However, the policy has also been leveraged to incentivize fuel switching. Electric vehicles sold into US markets are counted as 1.5 vehicles in calculating a manufacturer's average fuel economy. This means that a car maker would need to sell 50\% more conventional vehicles than EVs with the same fuel economy to reach their target in a given year. This mechanism has been successful in driving more alternative fuel vehicles into US markets. Credit multipliers have arguably been less successful in the European Union Renewable Energy Directive, where there have been significant market distortions for feedstocks such as used cooking oil.

This credit multiplier could also be applied on a sliding scale to further incentivize very low carbon fuels. An operator could receive, e.g., $1.1 \times$ credit value per $\mathrm{MJ}$ for fuels from $30 \mathrm{~g} \mathrm{CO}_{2} \mathrm{e} / \mathrm{MJ}$ down to $20 \mathrm{~g} / \mathrm{MJ}, 1.2 \times$ from 20 down to $10,1.3 \times$ from 10 down to 0 , and $1.5 \times$ for any negative $C$ pathway. This would both accelerate the production and uptake of very low $\mathrm{C}$ fuel pathways 


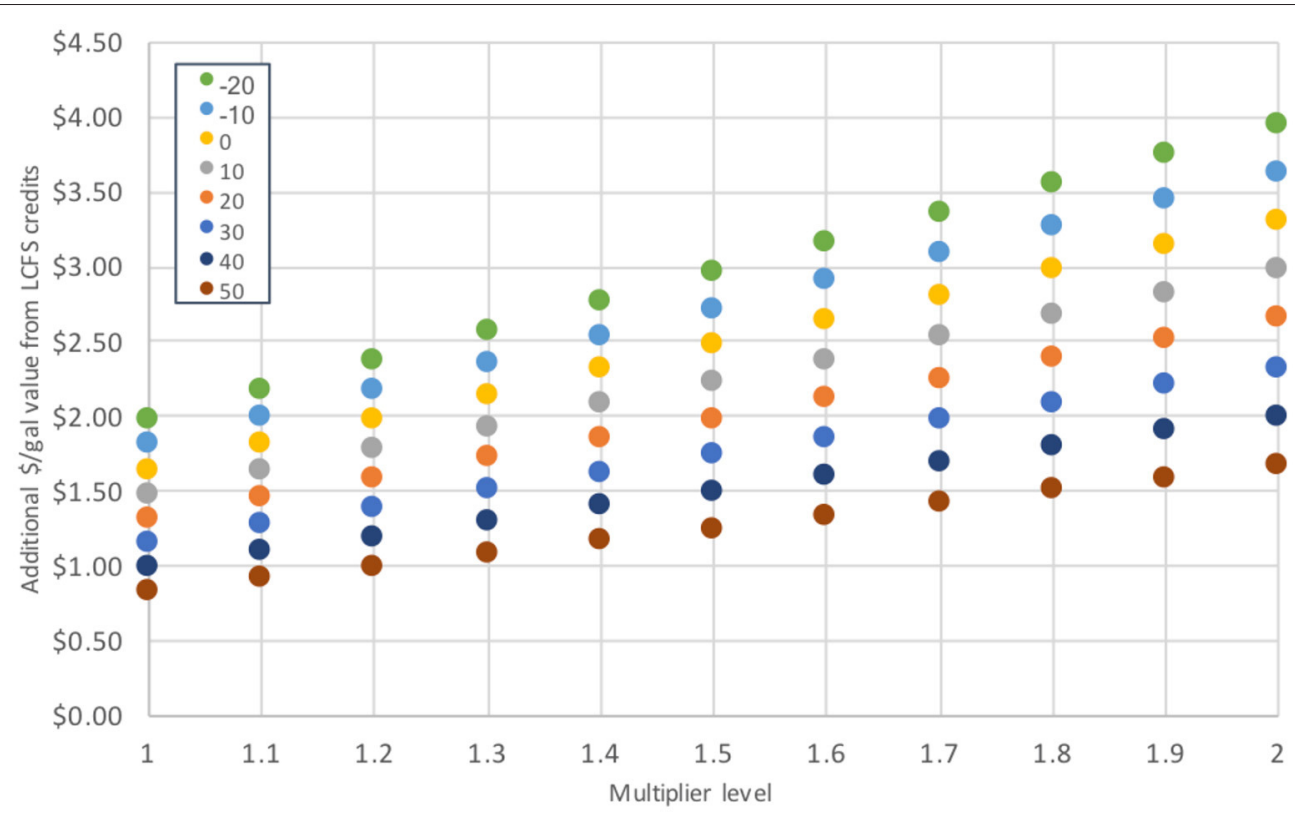

FIGURE 3 | Value of LCFS credits for delivery of a gallon of fuel as a function of that fuel's Cl and the multiplier level applied to that fuel type. We assume a fuel energy content of $81.51 \mathrm{MJ} / \mathrm{gal} \mathrm{LHV}$, a LCFS credit price of $\$ 200 / \mathrm{tCO}_{2} \mathrm{e}$, and displacement of California Reformulated Gasoline Blendstock for Oxygenate Blending (CARBOB) with $\mathrm{Cl}=101.69 \mathrm{MJ} / \mathrm{gal}$ LHV.

that will be critical for meeting future goals while still retaining the LCFS model of CI-dependent subsidy level.

The level of multiplier necessary to achieve the intended uptake of target fuel types would need to be determined through further study. It would be necessary to conduct a detailed technoeconomic analysis of facility profits at different multiplier levels to assess the multiplier necessary to drive significant uptake. Figure 3 presents the de facto per gallon subsidy created by the LCFS at different fuel CI values and different multiplier levels.

Implementing these additional incentives would mean reaching beyond the direct LCFS policy structure to achieve broader state goals. There is precedent, however, for using LCFS credits to incentivize activities not strictly within the bounds of the LCFS market. As discussed above, the allocation of credits for hydrogen fueling and fast EV charging infrastructure on a capacity rather than a delivery basis enables $A R B$ to leverage the LCFS program to achieve broader ZEV goals. As with a carveout, this policy would also reduce the amount of GHG reduction actually delivered by the LCFS program.

\section{Provide Additional Incentives for Ancillary Benefits}

ARB could provide additional incentives for very low-carbon and carbon negative fuel pathways which offer ancillary benefits to emissions reductions, such as wildfire risk reduction and air quality benefits. For example, it is clear that mobilizing woody forest residues that would otherwise be burned in open piles leads to a significant reduction in health-harming particulate emissions. ARB could consider offering additional incentives which recognize this benefit, especially where these residues would otherwise have been burned in non-attainment airsheds and/or near disadvantaged communities. ARB could also consider additional incentives for forest residue mobilization from designated high-hazard wildfire zones. However, in each of these cases, which reward local benefits, consideration would need to be given to interstate commerce and international trade issues. Further legal analysis is needed to determine how to reward benefits that are geographically limited without contravening potential limitations.

More broadly, ARB could ensure that the LCFS stimulates the best performing fuels across a variety of sustainability parameters. Fuels incentivized by the LCFS can offer significant environmental benefit, but this can't be taken as a given. Concerns abound regarding feedstock sourcing and its impacts on ecosystems, biodiversity, water resources, soil erosion, and other metrics of concern. Many of these considerations may be captured via the rigorous supply chain traceability already applied in the LCFS. However, others may not be tied to-or may even be inversely correlated with-lifecycle CI. ARB could consider third-party certification to ensure best practices are followed in feedstock sourcing across a variety of parameters, and also as a prerequisite to access additional LCFS incentives.

\section{DISCUSSION}

California's Low Carbon Fuel Standard (LCFS) is emerging as one of the most important policies to develop low-carbon and carbon-negative fuels. Yet, because the LCFS is designed to deliver the lowest-cost carbon intensity (CI) reductions 
possible in the transportation fuel system, it may fail to deliver technologies that would be poised to offer deeper decarbonization or other ancillary benefits to California's people and environment. This article contemplates administrative changes to the LCFS to further stimulate the commercialization of promising low-carbon and carbon-negative fuels. To do so, we examine promising technical pathways, their barriers to commercialization, and recent administrative actions by the CA ARB under the LCFS to promote novel lowercarbon fuels.

We propose three actions that ARB could undertake to promote commercialization within existing authorities. To commercialize low-carbon and carbon negative fuel, including those derived from forest residue feedstocks, ARB could: (1) embrace the most up-to-date science regarding lifecycle greenhouse gas emissions, (2) create additional, targeted incentives for very low-carbon or carbon-negative fuels through a volumetric technology carve-out or credit multiplier, and

\section{REFERENCES}

Aemetis, Inc. (2019). Aemetis Receives USDA Conditional Commitment for $\$ 125$ Million, 20-Year Financing of Riverbank Biorefinery. Available online at: Available online at: http://www.aemetis.com/aemetis-receives-usdaconditional-commitment-for-125-million-20-year-financing-of-riverbankbiorefinery/ (accessed February, 2021).

Baker, S. E., Peridas, G., Stolaroff, J. K., Goldstein, H. M., Pang, S. H., Lucci, F. R., et al. (2019). Getting to Neutral: Options for Negative Carbon Emissions in California (No. LLNL-TR-796100). Livermore, CA: Lawrence Livermore National Lab. (LLNL) doi: 10.2172/1597217

Breetz, H. L. (2017). Regulating carbon emissions from indirect land use change (ILUC): U.S. and California case studies. Environ. Sci. Policy 77, 25-31. doi: 10.1016/j.envsci.2017.07.016

California Board of Forestry and Fire Protection. (2020). Joint Institute Recommendations to Expand Wood and Biomass Utilization in California. Available online at: https://www.bioenergyca.org/wp-content/uploads/ 2020/11/Joint-Institute-Wood-and-Biomass-Utilization-Recommendat.pdf (accessed February, 2021).

Camia, A., Giuntoli, J., Jonsson, R., Robert, N., Cazzaniga, N.E., Jasinevicius, G., et al. (2021). The Use of Woody Biomass for Energy Production in the EU. Ispra: Joint Research Centre.

CARB (2017). Carbon Capture and Sequestration Program: 2016 Progress and Future Plans. Available online at: https://ww2.arb.ca.gov/sites/default/files/ 2018-12/CCS_Summary_Paper_April_2017.pdf (accessed February, 2021).

CARB (2018a). CARB Amends Low Carbon Fuel Standard for Wider Impact. Available online at: https://ww2.arb.ca.gov/news/carb-amends-low-carbonfuel-standard-wider-impact (accessed February, 2021).

CARB (2018b). Public Workshop to Discuss Implementation of LCFS. Available online at: https://ww3.arb.ca.gov/fuels/lcfs/lcfs_meetings/112818presentation. pdf (accessed February, 2021).

CARB (2018c). 2018 Proposed Amendments to the Low Carbon Fuel Standard Regulation and to the Regulation on Commercialization of Alternative Diesel Fuels. Retrieved from: https://ww3.arb.ca.gov/board/books/2018/092718/18-74pres.pdf (accessed February, 2021).

CARB (2019a). California Greenhouse Gas Emissions for 2000 to 2017 Trends of Emissions and Other Indicators. Available online at: https://ww3.arb.ca. gov/cc/inventory/pubs/reports/2000_2017/ghg_inventory_trends_00-17.pdf (accessed February, 2021).

CARB (2019b). Carbon Capture and Sequestration Project Eligibility. Available online at: https://ww2.arb.ca.gov/sites/default/files/2019-09/ccs_project_ eligibility_faq_9-12-19.pdf (accessed February, 2021).
(3) ensure that the LCFS stimulates the best-performing fuels across a variety of parameters.

California's efforts to commercialize carbon-negative fuels could hold large implications for global efforts to fight climate change. California's success could bolster the performance of the federal Renewable Fuels Standard (RFS), which also promotes lower-carbon fuels. Bioenergy with carbon capture and sequestration (BECCS) will likely play a large role in global efforts to address climate change. Yet successful commercialization of low- and carbon-negative fuels from forest biomass is far from certain, despite policy support from the LCFS. Absent intervention, the State risks missing an opportunity to develop and deploy these fuels, with global implications.

\section{AUTHOR CONTRIBUTIONS}

All authors listed have made a substantial, direct and intellectual contribution to the work, and approved it for publication.

CARB (2019c). 2018 LCFS Compliance Information and Credit Clearance Market Information. Available online at: https:/ww3.arb.ca.gov/fuels/lcfs/ 2018compliance-ccm_051519.pdf (accessed February, 2021).

CARB (2019d). Low Carbon Fuel Standard Workshop, July 31, 2019, Sacramento, C. A. Available online at: https://ww3.arb.ca.gov/fuels/lcfs/lcfs_meetings/ 073119presentation.pdf (accessed February, 2021).

CARB (2020a). Staff Summary Application No. D0005. Available online at: https:// ww3.arb.ca.gov/fuels/lcfs/fuelpathways/comments/tier2/d0005_summary.pdf (accessed February, 2021).

CARB (2020b). Low Carbon Fuel Standard. Available online at: https://ww2.arb.ca. gov/sites/default/files/2020-09/basics-notes.pdf

CARB (2021a). California Cap-and-Trade Program Summary of California-Quebec Joint Auction Settlement Prices and Results. Available online at: https://ww2.arb. ca.gov/sites/default/files/2020-08/results_summary.pdf (accessed February, 2021).

CARB (2021b). Weekly LCFS Credit Transfer Activity Report. Available online at: https://ww3.arb.ca.gov/fuels/lcfs/credit/lrtweeklycreditreports.htm (accessed February, 2021).

CARB (2021c). Low Carbon Fuel Standard Reporting Tool Quarterly Summaries. Available online at: https://ww3.arb.ca.gov/fuels/lcfs/lrtqsummaries.htm (accessed February, 2021).

CARB (2021d). LCFS ZEV Infrastructure Crediting. Available online at: https:// ww3.arb.ca.gov/fuels/lcfs/electricity/zev_infrastructure/zev_infrastructure. htm (accessed February, 2021).

Christensen, A., and Hobbs, B. (2016). A model of state and federal biofuel policy: feasibility assessment of the california low carbon fuel standard. Appl. Energy 169, 799-812. doi: 10.1016/j.apenergy.2016.01.121

Credit for Carbon Oxide Sequestration. (2011). 26 U.S. Code $\$ 45$ Q. Available online at: https://www.govinfo.gov/app/details/USCODE-2011-title26/ USCODE-2011-title26-subtitlechap1-subchapA-partIV-subpartD-sec45Q (accessed February, 2021).

Dihn, M., and Manternach, J. (2019). DOE Bioenergy Technologies Office 2019 Project Peer Review. Red Rock Biofuels. Available online at: https://www. energy.gov/sites/prod/files/2019/04/f61/Woody\%20Biomass\%20Biorefinery \%20Capability\%20Development_EE000DPA2.pdf (accessed February, 2021).

Exec. Order No. N-79-20. (2020). Available online at: https://www.gov.ca.gov/wpcontent/uploads/2020/09/9.23.20-EO-N-79-20-text.pdf (accessed February, 2021).

Exec. Order No. S-01-07 by Governor Arnold Schwarzenegger (2007). Available online at: https://web.archive.org/web/20081026081001/http://gov.ca.gov/ executive-order/5172/ https://ww3.arb.ca.gov/fuels/lcfs/lrtqsummaries.htm (accessed February, 2021). 
Farrell, A. E, Sperling, D., Brandt, A., Eggert, A., Farrell, A., Haya, B., et al. (2007). A Low-Carbon Fuel Standard for California Part 2: Policy Analysis. UC Berkeley: Transportation Sustainability Research Center. Retrieved from https:// escholarship.org/uc/item/1hm6k089 (accessed February, 2021).

Fawcett, A. A. (2010). Supplemental EPA Analysis of the American Clean Energy and Security Act of 2009 H.R. 2454 in the 111th Congress Appendix. Available online at: https://19january2017snapshot.epa.gov/sites/production/files/ 2016-07/documents/epasupplementalhr2454analysisappendix.pdf (accessed February, 2021).

Fridahl, M., Bellamy, R., Hansson, A., and Haikola S. (2020). Mapping multi-level policy incentives for bioenergy with carbon capture and storage in Sweden. Front. Clim. 2:604787. doi: 10.3389/fclim.2020.604787

GTI. (2019). Low-Carbon Renewable Natural Gas (RNG) from Wood Wastes. Available online at: https://www.gti.energy/wp-content/uploads/2019/02/LowCarbon-Renewable-Natural-Gas-RNG-from-Wood-Wastes-Final-ReportFeb2019.pdf (accessed February, 2021).

Jenkins, J., and Mansur, S. (2011). Bridging the Clean Energy Valleys of Death Helping American Entrepreneurs Meet the Nation's Energy Innovation Imperative. Breakthrough Institute. Available online at: https://s3.us-east-2. amazonaws.com/uploads.thebreakthrough.org/legacy/blog/Valleys_of_Death. pdf (accessed February, 2021)

Lane, J. (2018). Commercial time: Aemetis embarks on $\$ 158$ million cellulosic ethanol project in California. Biofuels Digest. Available online at: https://www. biofuelsdigest.com/bdigest/2018/03/08/commercial-time-aemetis-embarkson-158-million-cellulosic-ethanol-project-in-california/ (accessed February, 2021).

Little Hoover Commission. (2018). Fire on the Mountain: Rethinking Forest Management in the Sierra Nevada. Report \#242. Available online at: https://lhc. ca.gov/sites/lhc.ca.gov/files/Reports/242/Report242.pdf (accessed February, 2021).

Lomax, G., Lenton, T. M., Adeosun, A., and Workman, M. (2015). Investing in negative emissions. Nat. Clim Change 5, 498-500. doi: 10.1038/nclimate2627

Löw, P. (2019). The Natural Disasters of 2018 in Figures: Losses in 2018 Dominated by Wildfires and Tropical Storms. Munich, R. E. Available online at: https:// www.munichre.com/topics-online/en/climate-change-and-natural-disasters/ natural-disasters/the-natural-disasters-of-2018-in-figures.html (accessed February, 2021).

Lutsey, N., and Sperling, D. (2009). Greenhouse gas mitigation supply curve for the United States for transport versus other sectors. Transport. Res. Part D 14, 222-229. doi: 10.1016/j.trd.2008.12.002

Lynd, L.R., Liang, X., Biddy, M.J., Allee, A., Cai, H., Foust, T., et al. (2017). Cellulosic ethanol: status and innovation. Curr. Opin. Biotech. 45, 202-211. doi: 10.1016/j.copbio.2017.03.008

OEHHA. (2017). SB 535 Disadvantaged Communities. Available online at: https:// oehha.ca.gov/calenviroscreen/sb535 (accessed February, 2021).

Olsen, J. (2017). San Joaquin Valley Air Pollution Control District. Presentation at the Central Valley Summit on Alternatives to Open Burning of Agricultural Wastes, November 2017. Available online at: http://valleyair.org/cvsummit/ documents/presentations/Session02-Jessica-Olsen.pdf (accessed February, 2021).

Rathi, A. (2019). The Story behind the World's First Large Direct Air Capture Plant. Quartz. Available online at: https://qz.com/1638096/the-story-behindthe-worlds-first-large-direct-air-capture-plant/ (accessed February, 2021).

Red Trail Energy, LLC. (2019). Red Trail Energy Low Carbon Fuel Standard (LCFS) Design-Based Pathway Application - Carbon Capture and Storage Integrated with Ethanol Production. Available online at: https://ww3.arb.ca.gov/fuels/lcfs/ fuelpathways/comments/tier2/d0005_report.pdf (accessed February, 2021).

Rogelj, J., Shindell, D., Jiang, K., Fifita, S., Forster, P., Ginzburg, V., et al. (2018). "Mitigation Pathways Compatible with $1.5^{\circ} \mathrm{C}$ in the Context of Sustainable Development," in Global Warming of $1.5^{\circ} \mathrm{C}$. An IPCC Special Report on the Impacts of Global Warming of $1.5^{\circ} \mathrm{C}$ Above Pre-Industrial Levels and Related Global Greenhouse Gas Emission Pathways, in the Context of Strengthening the
Global Response to the Threat of Climate Change, Sustainable Development, and Efforts to Eradicate Povertyeds, eds V. Masson-Delmotte, P. Zhai, H.-O. Pörtner, D. Roberts, J. Skea, P. R. Shukla (Geneva: IPCC), 93-174.

San Joaquin Valley Air Pollution Control District. (2018). 2017-2018 Report to the Community San Joaquin Valley Air Pollution Control District. Available online at: https://www.valleyair.org/General_info/pubdocs/2017-18-AnnualReport.PDF (accessed February, 2021).

Sanchez, D., Zimring, T., Mater, C., Harrell, K., Muszynski, L., Edwards, B., et al. (2020). Joint Institute for Wood Products Innovation: Evaluation of Literature, Research Gaps, Partnerships, and Priorities. Board of Forestry and Fire Prevention. Available online at: https://bof.fire.ca.gov/media/9512/1-draft jiwpi-report_152020_ada.pdf (accessed February, 2021).

Schenuit, F., Colvin, R., Fridahl, M., McMullin, B., Reisinger, A., Sanchez, D. L., Smith, S. M., Torvanger, A., Wreford, A., and Geden O. (2021). Carbon dioxide removal policy in the making: assessing developments in 9 OECD cases. Front. Clim. 3:638805. doi: 10.3389/fclim.2021.6 38805

Springsteen, B., Christofk, T., York, R. A., Mason, T., Baker, S., Lincoln, E., et al. (2015). Forest biomass diversion in the sierra nevada: energy, economics and emissions. cal Ag 69, 142-149. doi: 10.3733/ca.v069n03p142

Stillwater Associates, L. L. C. (2018). The LCFS Credit Clearance Market: What Might Happen? Available online at: https://www.stillwaterpublications. com/wp-content/uploads/2018/11/CCM-Analysis-11-2018-hfw9723k.pdf (accessed February, 2021).

The White House. (2016). United States Mid-Century Strategy for Deep Decarbonization. Available online at: https://unfccc.int/files/focus/long-term strategies/application/pdf/us_mid_century_strategy.pdf (accessed February, 2021).

Townsend, A., and Havercroft, I. (2019). The LCFS and CCS Protocol: An Overview for Policymakers and Project Developers. Global CCS Institute. Available online at: https://www.globalccsinstitute.com/wp-content/uploads/2019/05/ LCFS-and-CCS-Protocol_digital_version.pdf (accessed February, 2021).

van der Zwaan, B., Keppo, I., and Johnsson, F. (2013). How to decarbonize the transport sector? Energy Policy 61, 562-573. doi: 10.1016/j.enpol.2013.05.118

Vogt-Schilb, A., and Hallegatte, S. (2014). Marginal abatement cost curves and the optimal timing of mitigation measures. Energy Policy 66, 645-653. doi: 10.1016/j.enpol.2013.11.045

Witcover, J. (2018). Status Review of California's Low Carbon Fuel Standard, 2011-2018 Q1 September 2018 Issue, UC Davis: Institute of Transportation Studies. Available online at: https:/escholarship.org/uc/item/445815cd (accessed February, 2021).

Zheng, S. (2019a). Is California's Low Carbon Fuel Standard Incentivizing Electric Vehicle Deployment? Clean Energy Finance Forum. Available online at: https:// www.cleanenergyfinanceforum.com/2019/05/29/is-californias-low-carbonfuel-standard-incentivizing-electric-vehicle-deployment (accessed February, 2021).

Zheng, S. (2019b). Is California's Low Carbon Fuel Standard Helping EV Deployment? GreenBiz. Available online at: https://www.greenbiz.com/article/ californias-low-carbon-fuel-standard-helping-ev-deployment (accessed February, 2021).

Conflict of Interest: The authors declare that the research was conducted in the absence of any commercial or financial relationships that could be construed as a potential conflict of interest.

Copyright (c) 2021 Sanchez, Fingerman, Herbert and Uden. This is an open-access article distributed under the terms of the Creative Commons Attribution License (CC $B Y)$. The use, distribution or reproduction in other forums is permitted, provided the original author(s) and the copyright owner(s) are credited and that the original publication in this journal is cited, in accordance with accepted academic practice. No use, distribution or reproduction is permitted which does not comply with these terms. 